\title{
NHUNGUARA: UMA COMUNIDADE RURAL DO VALE DO RIBEIRA
}

\author{
Mary Francisca do Careno \\ Unesp - Universidade Estadual Paulista - Assis - SP
}

\begin{abstract}
RESUMO: O Vale do Ribeira, localizado no litoral sul do Estado de São Paulo, apresenta várias comunidades rurais formadas por elementos da raça negra. Uma delas, Nhunguara, compōe-se enđogenicamente por uma única família - os Vieira -, representando os diversos bairros do município de Eldorado. Este artigo objetiva apresentar alguns antigos dados históricos sobre o Estado de São Paulo, relativos a esta região, que possam justificar a formação e a existência desses núcleos rurais ainda tăo característicos, apesar da grande aproximimaçăo corri a cidade mais desenvolvida do país.

ABSTRACT: Based on recorded statements and documents researched in libraries and archives, my purpose in this article is to present historic facts which justify the existence of black rural districts in Ribeira Valley. One of these black rural districts, Nhunguara, is entirely composed of only one black family - the Vieira's - with about one hundred and fifty members, which exemplifies the many black communities of Eldorado District - SP.
\end{abstract}

PALAVRA-CHAVE: Vale do Ribeira, comunidades rurais, ëscravidão, mineração, litoral de São Paulo. KEY-WORDS: Ribeira Valley, rural districts, slavery, mining, coast of São Paulo - Brazil.

1. O Vale do Ribeira, localizado no Estado de Sāo Paulo, apresenta hoje comunidades rurais constituídas essencialmente por famílias da raça negra.

A formação desses núcleos deve-se, segundo Petrone (1966, p. 57), à mineração ali existente desde o século XVI. Outros estudos, como os de Boccia-Malerbi (1977, p. 79) e outros dados constantes em relatórios de Província levam à conclusão de que tenham sido formados por negros fugidos ou das fazendas existentes nas redondezas ou de desembarques clandestinos de escravos no vasto litoral da região após a Lei Eusébio de Queirós ou ain- da de levantes de escravos acontecidos pouco antes da aboliçāo.

Este trabalho ${ }^{1}$ objetiva relatar esses e outros fatos históricos, alguns fatores geográficos que poderiam justificar a existência dessas comunidades, es-

1. Este trabalho é uma versão de parte do capítulo (“O Universo dos Informantes") da minha tese de doutoramento, defendida em maio de 1992, na Universidade Estadual Paulista - Unesp de Assis -SP, sob o título "A Linguagem Rural do Vale do Ribeira: a voz e a vez das comunidades negras". Deve-se esclarecer também que esses dados historicos servem como subsídios para a pesquisa, voltada particularmente para a área de Lingüística. 
pecificamente do bairro rural de Nhunguara. Tornase estranho que, em pleno final do século $X X$, a cerca de cento e cinqüenta quilômetros da capital, exista uma regiāo que se apresenta como um bolsão de pobreza dentro do Estado mais desenvolvido do país. Qual a causa do atraso? De onde surgiram essas comunidades negras? Como se formaram? Era desafiante perscrutar as razōes de scu atraso c composição, sobretudo se considerarmos que, em tempos não muito remotos, o local foi considerado um dos mais ricos da Nação.

2. Regiño acidentada, com altas montanhas, diversas cavcrnas e várzcas sujcitas a inundaçōes, o Valc do Ribeira localiza-se na parte sul do Estado de São Paulo. Com uma área global de $16522 \mathrm{~km}^{2}$, distribuída por dezcsseis municípios ${ }^{2}$, incluindo os portos de Iguape e Cananéia, a região, por suas condições naturais e por seus aspectos humanos, tornouse bem caracterizada e definida dentro do território de São Paulo.

Devido à sua posição de isolamento em que viveu durante longos anos, assemelhou-se, por isso mesmo, a um novo Estado dentro do Estado, conforme afirma Almeida (1955, p. 26) "conservando usos e costumes herdadọs ainda no Brasil Império, circunscrevendo toda uma vasta extensảo territorial", onde hoje congrega uma população de cerca de 260000 habitantes.

Historicamente condicionada por fatores limitantes de diversas ordens, sua agricultura, sua pecuária e sua indústria não acompanharam o acelerado desenvolvimento, verificado em outras áreas do Esta-

2. Neste trabalho, utilizo a classificaçāo da Fundaçōo IBGE que reúne, sob a denominaçāo de micro-regiāo homogênea, as RGs (Regiōes de Governo) de Registro e de ltapeva, que envolvem os dezesseis municipios em questāo, ou seja, RG de Registro: as cidades de Barra do Turvo, Cananeja, Eldorado, Iguape, hariri, Jacupiranga, Juquiá, Miracatu, Pariqüerassu, Pedro de Toledo, Registro e Sete Barras; da RG Itapeva as cidades que me interessam sâo Apiaí, Iporanga e Ribeins. do. Dentre esses fatores, destacam-se tanto a falta de meios de transporte quanto a própria situação geográfica que condiciona o continuado isolamento de áreas próprias para a atividade produtiva: a dimensão das lerras agriculturáveis ainda hoje ć bastantc reduzida, (cerca de $5 \%$ da área total), seja por causa do relevo bastante acidentado, seja pela baixa potencialidade do solo. A situação foi atenuada, em 1966, pela abertura da rodovia BR 116, que serve a algumas de suas áreas. Suas cidades, relativamentc pobres e de pequena população, estão ligadas através do rio Ribeira de Iguape e seus aflucntes, que até o início do século eram a única via de acesso a outras regiōes do Estado. Por conseguinte, essa situação indefinida e vacilante condicionou a năo aplicaçāo de investimentos necessários, de modo que o círculo vicioso do atraso do setor primário se repete monotonamente.

2.1 A comunidade ou bairro Nhunguara, objeto deste artigo, encontra-se no município de Eldorado Paulista (antigamente denominado Xiririca), à margem direita do Rio Ribeira de Iguape. A cidade, assim como toda a regiāo, era bastante conhecida desdc o tempo do descobrimento do Brasil, pelas riquezas minerais que acumulava em seu solo, conhecidas mesmo ern meados do século XVI, quando já contava com a presença de colonos europeus ${ }^{3}$.

Segundo pesquisas do MIS (Museu da Imagem e do Som, 1980), supóe-se que, entre os anos de 1502 e 1510 , alguns portugueses (entre os quais o quase lendário Bacharel de Cananéia) ${ }^{4} \mathrm{e}$ alguns es-

3. Iporanga era ou1ro local também conhecido por suas minas de ouro. Nhunguara, uma das comunidades - tema do trabalho -, localiza-se na divisa entre Iporanga e Eldorado Paulisia.

4. Bacharel foi uma figura bastante polêmica na hisıória de Cananéia. Almeida (1955), acredita ter sido o Mestre Cosme Fernandes, "provavelmente degredado de alguma expediçāo espanhola - que para ca veio a fim de defender as terras de Espanha constantes no Tratado de Tordesilhas". Há também a hipótese de que ele tenha vindo na segunda missão exploradora portuguesn, enviada pot Dom Manoel. Em arquivos curopeus, consultados por Francis- 
pantóis - degredados ou náufragos - marcaram com sua presença um esboço de povoamento que se estendia desde São Vicente até os sítios das futuras povoaçōes de Jguape e Cananéia.

Quando Martim Afonso de Souza aportou em Cananéia em 12.8.1531, conforme Almeida (1955, p. 31), já encontrou esse pequeno grupo de indivíduos, com alguns naturais do país e, supostamente, já habitavam há cerca de trinta anos neste ponto da costa sul-paulista. Acredita-se que Martim Afonso de Souza interessou-se pelas riquezas da região por diversas informaçóes obtidas na Península Ibérica com expedicionários. Incentivou a organização de Bandeiras e fundou povoados pressupondo, segundo o autor já citado, à página 31, que "se na costa norte, com os franceses, existia a costa do pau-brasil, na costa sul, haveria a costa do ouro e da prata".

Houve várias notícias sobre o ouro paulista. Segundo Ellis Jr, (1944, p. 271), Heliodoro Eoban investigou ouro entre 1570 e 1584 ; entre 1579 e 1592 , Jerônimo Leitão fez buscas até Paranaguá; em 1588, 1590 e 1591 Cavendish esteve em Santos e havia ouro por lá; desde 1567 Afonso Sardinha e seu filho mameluco do mesmo nome, auxiliados por Clemente Álvares, descobriram e mincraram ouro nas serras de Jaguamimbaba e de Jaraguá, Parnaíba e Sorocaba. Latif (p. 27) lembra ainda que Brás $\mathrm{Cu}-$ bas também explorou ouro na vertente maritma da serra; os padres jesuítas construíram conventos próximos às suas mineraçōes na orla do planalto e no Vale do Ribeira, no lugar onde hoje está a cidade de Registro, onde foi construído um posto fiscal. Além disso, foram criadas casas de fundição em Iguape (em 1630), Sāo Paulo e Paranaguá, onde o ouro particular era derretido e cobrava-se o direito senhorial do quinto percebido pela Coroa.

co A. Varnhagen, consta que no Diário de Navegação de Martim Afonso de Souza, está escrito que o navegador encontrou um bacharel português degredado há trinta anos $\mathrm{em}$ Cananéia (Tribuna da Ribcira de 13.2.1982, p.5).
Apesar de todas essa informaçōes de descoberta e exploraçāo, Ellis Jr csclarece que não foi tão grande a atividade do paulista na mineraçāo, pois: a) não foi um chamariz de grandes massas demográficas como o foram as minas de ouro no setentismo; b) não houve os grandes fenômenos sociais c cconômicos que as Gerais testemunharam no decorrer do século XVIII. O autor esquece-se, contudo, de que em Minas a população brasileira era bem maior e o intercâmbio cultural entre a colônia e a metrópole era bem mais intenso.

Se sabemos que, em 1630, foi fundada em Iguape a primeira casa de fundiçāo de ouro do Brasil, há que se considerar que o Reino de Portugal certamente tinha conhecimento das riquezas da regiāo. Há que se considerar também, neste assunto, a importância do trabalho dos negros na mineração do Vale do Ribeira, embora a origem de sua vinda ao Vale não tenha data precisa. Bastide (1954, p. 23) assinala que a origem do tráfico negro em São Paulo ainda requer estudos aprofundados $\mathrm{e}$, ainda que encontremos o termo "negro" em documentos antigos de missionários, ele apresentava um sentido mais vasto do que hoje the damos: designava tanto o "tapuipiranga" ou "gentio da terra" como o "tapanhuano"ou "gentio de Guiné", ou seja, o termo "negro" era utilizado tanto para os negros africanos como para os índios. Estes eram chamados de "negro", "gente forra", "escravos", pois tratava-se de um meio de iludir a lei que proibia a escravização do ameríndio. Fica difícil, portanto, determinar a data da vinda dos primeiros negros à regiāo paulista.

O número de africanos nos primeiros tempos foi bastante reduzido, visto que a base vicentina era de apresamento de ameríndio. Os paulistas não iriam importar africanos para concorrer com a mercadoria que ofereciam: o índio. Para Ellis Jr (op.cit., p. 383) é possivel que esporadicamente um ou outro africano aparecesse. Moura (1988, pp. 221-222, com especial atenção à nota de rodapé), também nāo preci- 
sa a data, assinalando que os boçais "penetraram em Sāo Paulo em fase anterior ao surto cafeeiro c, embora nảo fosse insignificante o seu número, nāo pesaram demograficamente - no conjunto da população escrava - de forma absoluta".

Assim, fica realmente difícil saber, com certeza, a data da entrada dos primeiros negros no Estado de Sāo Paulo. Segundo o pesquisador de Iguape, Roberto Fortes, em reportagem ao jornal $A$ Tribuna do Ribeira (12.5.1982, p. 8), "os primeiros negros africanos foram introduzidos no Vale do Ribeira [...] sendo inicialmente empregados na mineração de ouro, que nessa época se intensificáa cm Iguape". A regiāo, scgundo ele, "foi um dos maiores centros de mercantilizaçāo de escravos da América Latina"s.

2.2 Foi a exploração do ouro que, no século XVII, principalmente, marcou a situaçāo econômica da região, da qual se beneficiou, sobretudo, o núcleo de Iguape.

As atividades econômicas, no entanto, declinaram a partir do final do século, início do XVIII, quando a descoberta de minas de ouro, nos sertōes de Cataguazes (Minas Gerais), determinou o êxodo de numerosos moradores da regiāo da Ribeira com suas famílias e escravos, para aquelas paragens mineiras.

2.3 Segundo relatório (1973) da antiga SUDELPA (Superintendência do Desenvolvimento do Litoral Paulista), a situaçāo da região até aquela data

5. É lamentável que arquivos importantes para a hisıoria do Vale e, consequientemente, para a escravidäo, tenham sido destruídos. Segundo consta em $A$ Tribuna do Ribcira (1982, p. 5), "o arquivo de Cananéia foi simplesmente queimado. $O$ de Sĩo Vìcente desapareceu na invasīo de piratas ingleses $\mathrm{cm}$ 1580. O da Bahia foi destruído por colonizadores holandeses e o de Lisboa perdeu-se, $\mathrm{cm} 1755$, depois de um violento terremolo". Assim, resta-nos a consulta a documentos esparsos em São Paulo, no Rio de Janeiro, na Bahia e em acervos particulares. Também e, principalmente, resta o recurso à história oral, aos relatos das pessoas mais velhas dos locais estudados. pouco mudara, pois "à baixa porcentagem de terras aproveitáveis para a lavoura, soma-se o efeito de uma estrutura fundiária anacrônica, que as mantêm inaproveitadas, ou aproveitadas com baixos índices de rendimento. Também o clima, com suas altas temperaturas e elevadas taxas de umidade relativa, representa um obstáculo considerável, pois fornece o habitat ideal para toda sorte de agentes patogênicos e ervas daninhas".

Essa situação talvez seja a causa de a regiāo ter de uma populaçāo rarefeita, mal distribuída, pouco urbanizada e tecnicamente mal cquipada para fazer frente a uma economia mais desenvolvida como as de outras regiōes do Estado.

3. A comunidade negra de Nhunguara, como já dissemos, encontra-se localizada no município de Eldorado.

Com uma área terrestre de $1721 \mathrm{~km}^{2}$, a cidade pertence à Regiāo Administrativa do Município de Registro e a população total em 1991 cra de 13148 habitantes". Abriga, como todo o Vale, uma população rural maior do que a urbana, sendo 5790 na área urbanizada e 7358 habitantes na área rural. Essa situação certamente vai se inverter com a construçāo das barragens, que o grupo CBA da Votorantin pretende construir ao longo do Rio Ribeira de Jguape. O deslocamento e a desestruturaçāo grupal dos habitantes da regiāo ribcirinha serāo terriveis c inevitáveis.

Os problemas de Eldorado Paulista são os mesmos já levantados para toda a região pelos diferentes organismos que fazem estudos referentes a cla, a saber, economia estagnada, precariedade do mejo de transportc, população esparsa e isolada, representan-

6. Dados fornecidos pela Sinopse Preliminat do Censo Demográfico/ Fundaçẫo Instîtuto Brasileiro de Geografia e Estalística. vol.6 (1991). Rio de Janeiro, JBGE. Populaçāo residente em 1991 por situaçāo do domicílio, com indicação da população da sede municipal, área total e densidade demografica em 1991. 
do, segundo Brandão (apud QUEIROZ, 1983, p. 38), a mais baixa densidade demográfica do Estado de Săo Paulo. Segundo a Sinopse/1991, em 1.9.1991, cra de $7,64 \mathrm{hab} / \mathrm{km}^{2}$. Região predominantemente rural, o seu habitante típico é o "caiçara". Grande parte da população, pobre e analfabeta, é egressa de zona nāo-urbana ou descendente de migrantes rurais, sem qualificação profissional. Pouco accsso tem à efetiva escolarizaçāo $\mathrm{e}$ à língua culta $\mathrm{e}$, conseqüentemęnte, a mobilidadc social é pequena.

Apesar de, segundo o autor, o elemento negro ter uma influência reduzida sobre a exploraçāo da banana - uma das bases econômicas da regiāo - $\mathrm{em}$ todo o Vale, destaca-se a presença significativa do descendcnte africano, nos municípios de Iporanga e Eldorado "o que talvez possa ser atribuído ao trabalho de mineração que antigamente era realizado por escravos. Após a Aboliçāo teriam os escravos e seus descendentes permanecido na área, transformados em roceiros, ocupando as terras desvalorizadas cóm o término da mineração"7.

Eldorado Paulista situa-se à direita do Rio Ribeira, o mais importante rio da regiāo, que nasce no Estado do Paraná, penetra no Estado de São Paulo pelo município de Ribeira, atravessando os municípios de Apiaí e Iporanga, passa por Eldorado na direção oeste-leste e vai até Iguape, no Oceano Atlântico. Há outros rios que dão nome a localidades negras rurais da regiāo: Nhunguara, André Lopes, Cordas, Sapatu, Bananal Grande, Bananal Pequeno, Abobral de Baixo, Abobral de Cima, Sāo Pedro, Pilōes e outros.

4. Na época em que toda a regiăo do Vale do Ribeira formava o vasto município de Iguape, o território era dividido em diversas freguesias ou bairros. Iguape exercia grande influência sobre todos eles, especialmente sobre Iporanga e Apiaí, de-

7. Queiroz, op. cit., pp. 38-39. tentoras das minas de ouro mais ricas do Ribeira, juntamente com Xiririca. Na divisa, entre os atuais municípios de Iporanga e Ėldorado Paulista, localiza-se o bairro rural ou a comunidade negra de Nhunguara.

Sua origem é controvertida. Remonta talvez a uma expedição de ouro chefiada por um médico, Sebastiāo Pereira dạ Fonseca, que teria fundado a comunidade em $1889^{8}$. Há fontes históricas que comprovam a existência dessa comunidade rural como sendo realmente um local de extraçāo de ouro. Fortes (1982, p. 6), traz, por exemplo, à informação, conhecida através de documentos pesquisados por ele, de que a partir de 1630 , quando foi fundada na Vila de Iguape a Casa de Oficina Real da Fundiçāo do Ouro, todo o metal encontrado sobretudo nas localidades de Iporanga, Xiririca e Itatins era transformado em barras: Almeida (op..cit., p. 33) refere-se a um documento publicado pelo pesquisador Young no qual há uma petiçāo de Domingo Roiz Cunha, de 1655 , que faz referências às minas de Ivaporunduva, Iporanga, Apiaí e Sorocaba. As localidades assinaladas ficam muito próximas de Nhunguara e, como antigamente a delimitaçăo das terras não era a mesma que hoje encontramos, nāo se descarta a hipótese de que havia mina aurífera no local.

Em suma, o nome de Nhunguara está sempre ligado às questōes da extração de ouro na época áurea da região. Para justificar a presença de tantos negros no bairro, podemos recorrer à seguinte notação encontrada em Krug (1912, p. 290): "os lavradores que viverāo aqui para tirar ouro matarāo uns aos outros e por isso os brancos desapareceram e só os pretos se conservarāo até hoje no ribeirão guaporunduva, Anhanguera [sic], etc."

Essa comunidade rural é banhada pelo Ribeirāo de Nhunguara que, segundo Almeida (op.cit., p. 11), todos escrevem Nhanguera ou Anhanguara.

8. Folha de São Paulo, 1986, p. 25. . 


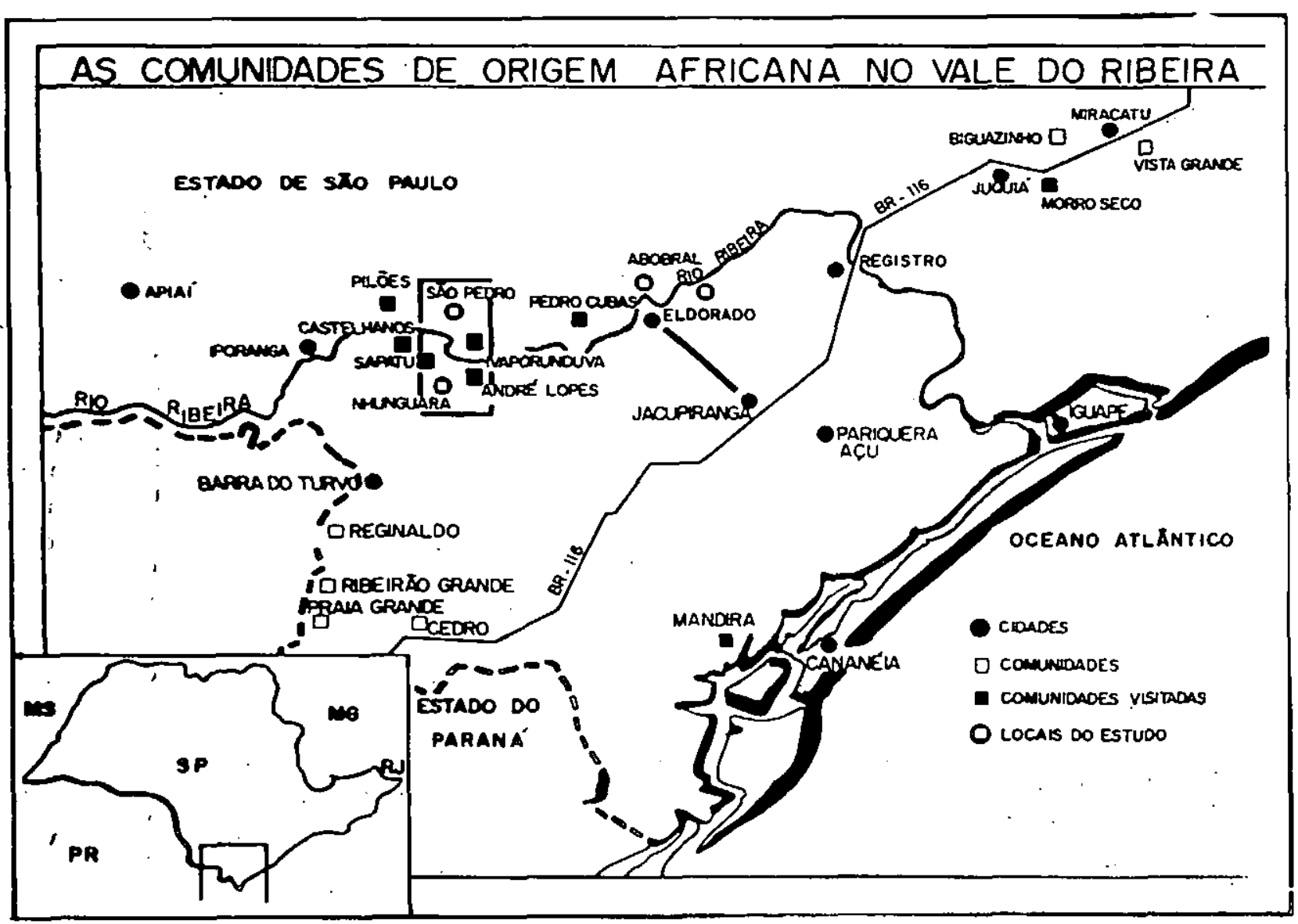

Para o Pe. Mendonça, Anhanguara significa talvez "o pavor que concebiam dos estrondos freqüentes das exalações dos montes e lugares próximos que se ouvem do Nhanguára. Esse ribeirāo serve de divisa entre os municípios de Iporanga e Xiririca".

Nhunguara é uma das comunidades mais organizadas e ativas do Vale. As cerca de quarenta e cinco famílias que ali residem plantam arroz, feijāo, milho e banana somente para o consumo. Criam por-

9. O Pe. Mendonça foi quem organizou os primeiros documentos, referentes ao Livro de Tombo de Xiririca. Este é um antigo livro da igreja, onde se lançavam os mais importantes acontecimentos do lugar $\mathrm{e}$ outros assuntos de interesse geral. cos, galinhas e patos. A religiāo católica está presente nos cultos dominicais e nas missas realizadas mensalmente.

A ligação entre uma habitação e outra é feita, como nas demais comunidades que visitei, através de trilhas precárias, sinuosas e mal conservadas. Há esse isolamento dentro da uniāo que impera entre os habitantes, pois algumas casas distanciam-se bastante das demais, mas seus habitantes comparecem aos cultos religiosos e às discussōes de grupo de interesse para todos. Ademais, pertencem a uma única família - os Vieira - e, com esse parentesco, sentem-se incluídos no conjunto do bairro. 
Essa característica de parentesco, predominante nas comunidades negras visitadas, inclui-se na gencralidade dos traços levantados por Antonio Candido Mello e Souza para o que ele chamou de unidades de povoamento e de seus componentes (1975, especialmente os capítulos 3 e 4). Outras características citadas por ele são, além do isolamento, a posse e a disponibilidade de terras, o trabalho doméstico, o auxílio vicinal e a ampla margem de lazer. Acrescentaríamos a isso, a relaçăo de parentesco acima citada, com uma endogamia acentuada, o que faz com que os habitantes de toda a região que se estende de Eldorado até Iporanga formem uma grande família, já que, em depoimentos gravados, os entrevistados possuem parentes nos diversos bairros espalhados pelo Vale, formando uma rede de laços de sangue tão ampla, que se torna difícil encontrar a descendência e ascendência de toda a família Vieira. Seria a exploração das minas de ouro da região ou poderia ser a fuga de escravos chegados nos navios, atracados nos portos de Iguape e de Cananéia que contribuíram para a formação dos núcleos da regiäo? Ou eles scriam remanescentes de quilombos, formados de escravos fugidos dos navios atracados clandestinamente no imenso litoral sul-paulista após 1850 ?

5. Retomando algumas considerações feitas no início da pesquisa, cremos que é preciso resgatar ainda antigos documentos do Vale, espalhados em pelo menos quatro cidades do Estado de São Paulo, ou. seja, Iporanga, Apiaí, Itapeva, Sāo Paulo (Arquivo Histórico do Estado - seçāo de história, principalmente) e os documentos referentes à escravidão no Vale do Ribeira que se encontram nesses locais e na Cúria Diocesana em Registro. As informaçōes que conseguimos e que podem, à primeira vista, confirmar a hipótese de formaçāo desses núcleos rurais negros na regiāo são três: a) documentos antigos sobre lavras de ouro na região;

b) documentos antigos que se encontram no Arquivo do Estado e denunciam ou deixam supor as fugas em massa de escravos para a regiāo e;

c) o relato dos próprios moradores, quando dizem nāo saber sobre a formação dos bairros rurais negros e quando relatam, insistentemente, do medo que os pais tinham em deixar as crianças brincarem livres.

Segundo um documento datado de 29.4.1793, constante no Arquivo do Estado, sob o número de ordem 347, Romam de França descobriu uma lavra em um córrego vizinho, em Nhungóara [o grifo é nosso].

Em outro documento de 2 de junho de 1798 (ou 1791?), sob a mesma ordem enviado pelo mestre de Campo José(T)omas(I)ecemos, solicita-se auxílio ao Guarda-mor Antonio Bueno da Silveira "p.effeito de descubrim hum corrego, vila y riacho incognito nos matos du Anhaunguara".

Em outro conjunto de documentação antiga, existe um grande número de telegramas de delegados de polícia e de presidentes de província, denunciando, em 1886 e 1887, primeiramente, os tumultos de escravos fugidos e que, após saques nas cidades vizinhas, debandavam para as matas da regiāo de Santos. Há a seguinte circular, datada de 22.10.1887, procedente do Rio de Janeiro para o Presidente da Província de São Paulo.

Não há novidades; os escravos que se haviam sublevado em São Paulo em número de sessenta debandaram, em pequenos grupos, internando-se nas matas da Serra do Cubatāo Força publica os persegue para aprisionalos tranquilidade na provincia.

E encontramos um outro telegrama, datado de 20.10.1887, do Estado de Cubatão, do Coronei Canto e Mello ao Exmo. Snr. Visconde do Parnahyba. 
Negros hoje desperçoos no alto da Serra, volta Cubatāo impedir que se apresentem em Santos como pretendem em pequenas fracçōes.

Sob o número de ordem 5577, no mesmo Arquivo do Estado, há notícias sobre desembarque de escravos boçais em diversas localidades paulistas, particularmente no litoral. No doc. $n^{2} 47$, há um documento que denuncia desembarque clandestino em Santo Antonio de Juquiá; no doc. $n^{2} 4$ há notícias de um possível desembarque clandestino nas redondezas de Xiririca.

Sob o número de ordem 4453, há uma carta (reservada) de Itu, em 22.1.1853, do Sr. João Guilherme Aguiar Whitaker, comunicando ao Sr. Jozino do Nascimento de São Paulo, o "desembarque em grande escalla nas immediaçōes da Villa d'Iguape e que os africanos desembarcadas [...] achāo-se actualmente acculttos nas matas situadas entre Juquiá, que desagoa na Ribeira de Iguape, e a Villa de Itapetininga e Una".

Por essas notícias, nảo podemos descartar a possibilidade de que as comunidades negras do Vale,

\section{Bibliografia}

ALMEIDA, Antonio Paulino de. "Memória Histórica de Xirírica (Eldorado Paulista)". In: Bolctim do Departamento do Arqui. vo do Estado de Sāo Paulo. vol. 14, 1955.

BASTTDE, Roger. "O Negro em São Paulo". In: Instituto Histórico e Geográfico (org.). Sáo Paulo cm Quatro Sćculos. São Paulo, 2:23-40, 1954.

BOCCIA, Ana M. M. e MALERBI, Eneida M. "O Contrabando de escravos para São Paulo". Revista de Historia. $n^{\mathbf{2}} 112$, ano XXVIII:321-379, out.-dez., 1977.

CANABRAVA, A. P. "Um Desembarque Clandestino de Escravos em Cananéia". Revista de História . 4 (1): 559-562, out.dez. 1950 . entre elas São Pedro e Nhunguara, tenham sido formadas inicialmente por escravos fugidos. Os escravos teriam fugido nāo só dos navios negreiros, que atracavam nos portos de Iguape c Cananéia, mas também das fazendas e sítios de localidades vizinhas. É possível também que tenham feito parte de grupos de escravos, chegados clandestinamente após a Lei Eusébio de Queirós, de 14.10.1850. Esta, retomando a lei de 1831, que declarava extinto o tráfico, estipulou penas severas aos infratores ${ }^{\mathrm{t0}}$.

No âmbito geral, esperamos que o trabalho sirva se nāo para uma fonte de consulta, pelos menos para dar a conhecer uma regiāo do Estado, esquecida e pobre e também fazer conhecer o mundo, o universo dos habitantes. Com isso esperamos aproximar-nos com bases mais consistentes da veracidade ou nāo de nossas hipóteses e, quiçá, oferecer um texto que, citando a poetiza negra Geni Guimaräes, possa ser útil àqueles que no afeto singular do acontecimento tão bem agasalharam a timidez e o medo de minha naçāo interna.

10. Ver Boccia / Malerbi (1977) e Canabrava (1950).
CANDIDO, Antonio. Os Parcciros do Rio Bonito. 3.ed. São Paulo, Duas Cidades, 1975.

ELLIS JR., Alfredo. Captulos da História Social de São Paulo. São Paulo, Nacional, 1944. . "O Ciclo do Muar". Revista de Historia. 1(1):73. 81, jan.-mat., 1950.

FORTES, Roberto. "História do Vale". A Tribuna do Ribcira. Registro-SP, 10 nov. 1982 , p. 6.

FORTES, José Rubens de Oliveira c FORTES, Roberto M. $C \mathrm{~cm}$ Anos de Aboliçāo: csłudo histórico sobre a escravidāo no Valc do Ribeira. 1988. (apostila datilografada).

KRUG, Dr. Edmundo. “Xiririca, Ivaporundyba c Yporanga”. Revis. 
ta do Instituto Histórico e Geográfico de São Paulo. XVII, . 259-291, 1912.

LATIF, Miranda de Barros. Minas Gerais: a aventura portugucsa, a obra paulista, a capitania c a provincia. Belo Horizonte, Livraria Cultura Brasileira, (s/d).

MIS (Museu da Imagem e do Som). Vale do Ribeira. Cadernos do MIS.I. São Paulo, 1980.

MOURA, Clóvis. Rebcliōcs da Senzala. 4.ed. Porto Alegre, Mercado Aberto, 1988.

PETRONE, Pasquale. A Baixada do Ribeira: cstudo de geografia humana. Sāo Paulo, FFCLUSP, Boletim n 14, 1966.

QUEIROZ, Renato da Silva. Caipiras Negros no Vale do Ribeira: um estudo de antropologia cconómica. Sāo Paulo, FFLCH/ USP, 1983.
SINOPSE Preliminar do Censo Demográfico - 1991. Recenscamento Geral do Brasil. Fundaçăo Instituto Brasileiro de Geografia e Estatística. $n^{0} 19$. Sẩ Paulo-Rio de Janeiro, v. 6, 1991.

SUDELPA (Superintendência do Desenvolvimento do Litoral Paulista). Caracterização Físico-econômico-social. Săo Paulo, 1973.

SEADE (Fundação Sistema Estadual de Análise de Dados). Anuá. rio Estatistico do Estado de São Paulo-1988. São Paulo, 1989.

Jornal A Tribuna do Ribeira. Registro-SP

Jornal Folha de São Paulo. Săo Paulo-SP.

Jornal O Estado de São Paulo/SP 19.2.1989.

Documentos Históricos do Arquivo do Estado de Sāo Paulo. 